\title{
Нелинейная ТГц фотоника жидкостей
}

\author{
А.П. Шкуринов ${ }^{1)}$, А.В. Балакин ${ }^{1)}$, И.В. Котельников ${ }^{2)}$, В.А. Макаров ${ }^{1)}$, П.М. Солянкин ${ }^{3)}$
}

${ }^{1}$ Физический факультет и Международный учебно-научный лазерный иентр МГУ имени М.В.Ломоносова, 19991, ГСП-1, г. Москва, Ленинские горы, дом 1, строение 2

эл.nочта: ashkurinov@physics.msu.ru

${ }^{2}$ Федеральное государственное бюджетное учреждение науки Институт ядерной физики им. Г.И. Будкера Сибирского отделения Российской академии наук, 630090, г. Новосибирск, проспект Академика Лаврентьева, дом 11

${ }^{3}$ Институт проблем лазерных и информационных технологий РАН - филиал Федерального государственного учреждения «Федеральный научно-исследовательский центр» Российской академии наук», 140700, Московская область, г. Шатура, улица Святоозерская, дом 1

DOI 10.34077/RCSP2019-45

Мы представляем результаты исследования широкого круга явлений, возникающих при взаимодействии мощных фемтосекундных лазерных импульсов оптического диапазона и импульсного терагерцового (ТГц) излучения в жидкости.

Впервые зарегистрирован эффект поляризационного взаимодействия трех эллиптически поляризованных волн, распространяющихся в изотропной нелинейной жидкой среде - жидком азоте, при этом частота одной из волн находилась в ТГц диапазоне [1]. Также впервые показана возможность преобразования оптического излучения фемтосекундной длительности в ТГц излучение в жидком азоте [2]. Исследована зависимость величины выхода ТГц излучения, генерируемого вблизи свободной поверхности жидкости, от условий фокусировки лазерного излучения при переходе через границу раздела, отделяющую газообразную фазу среды от ее жидкой фазы. Изучены особенности «одноцветного» и «двухцветного» режимов генерации ТГц излучения в жидком азоте. Представленные экспериментальные результаты подтверждены теоретической интерпретацией и явно указывают на принципиальное отличие механизмов, приводящих к генерации ТГц излучения в жидкой и в газообразной средах при воздействии на них фемтосекундными лазерными импульсами.

На основе предложенной модели, развитой в рамках феноменологического подхода, показано, что как ионизация среды так и ее нелинейная восприимчивость играют значительную роль в генерации ТГц излучения в жидком азоте. Мы предположили и обосновали, что подвижность ионов и электронов в жидкости может играть существенную роль в этом процессе, формируя квазистатическое электрическое поле с помощью механизма амбиполярной диффузии. Это квазистационарное поле участвует в генерации ТГц излучения за счет нелинейного эффекта третьего порядка. Когерентное поляризационно-чувствительное нелинейное взаимодействие трех эллиптически поляризованных электромагнитных волн, одна из которых на ТГц частоте, при их совместном распространении в нелинейной изотропной среде, также хорошо описывается в рамках феноменологического подхода. Мы показали, что Керровская нелинейность изотропной среды, возникающая в результате четырехволнового смешения $\Omega \approx 2 \omega-\omega-\omega\left(\omega_{\mathrm{T \Gamma ц}}=\Omega\right)$ благодаря эллиптически поляризованным волнам на основной и удвоенной частотах, распространяющимся коллинеарно с ТГц излучением, оказывает заметное влияние на состояние поляризации ТГц излучения. Наблюдаемые при этом изменение эллиптичности поляризации ТГц волны и вращение главной оси эллипса поляризации, могут быть хорошо описаны в рамках физического подхода, аналогичного использованному для объяснения самовращения эллипса поляризации впервые описанного в 1964 году Макером и др. [3], но расширенного для случая многочастотного взаимодействия.

Исследования выполнены при частичной поддержке Российского Фонда Фундаментальных Исследований (проекты №18-52-16016, 18-29-20104, 17-02-01217) и частичной поддержке Министерства науки и высшего образования в рамках выполнения работ по Государственному заданию ФНИЦ «Кристаллография и фотоника» РАН.

\section{Лuтература}

[1] A.V.Balakin, S.V.Garnov, V.A.Makarov, N.A.Kuzechkin, P.A.Obraztsov, P.M.Solyankin,

A.P.Shkurinov, and Y.Zhu, Opt. Lett. 43, 4406-4409 (2018).

[2] A.V.Balakin, J.-L.Coutaz, V.A.Makarov, I.A.Kotelnikov, Y.Peng, P.M.Solyankin, Y.Zhu, and A.P.Shkurinov, Phot. Res., Posted 11 Apr 2019.

[3] P.D. Maker, R.W. Terhune, and C.M. Savage, Phys. Rev. Lett. 12, 507 (1964). 